\title{
PROFIL PERESEPAN OBAT ANTIHIPERTENSI PERIODE JANUARI SAMPAI DENGAN DESEMBER 2019 DI PUSKESMAS TANGKAHAN DURIAN
}

\author{
Ovalina Sylvia Br. Ginting ${ }^{1}$, Nahdiah Taroreh ${ }^{2 *}$ \\ 1,2Program Studi Farmasi, Fakultas Ilmu Kesehatan, Universitas Haji Sumatera Utara, \\ Medan, Indonesia \\ Email: nahdiahtaroreh@gmail.com \\ * corresponding author
}

\begin{abstract}
Abstrak
Hipertensi merupakan suatu keadaan dimana terjadi peningkatan tekanan darah di atas ambang batas normal. Hipertensi perlu mendapat penanganan, salah satunya adalah upaya penanganan antihipertensi dengan terapi pemberian farmakologis antihipertensi. Penelitian ini bertujuan untuk mengetahui Kualitas Produk Obat Generik Berlogo (OGB) PT. Phapros Tbk Medan di Wilayah Medan Timur dan untuk mengetahui Profil Peresepan Obat Antihipertensi Periode Januari 2019 sampai dengan Desember 2019 di Puskesmas Tangkahan Durian Kecamatan Berandan Barat Kabupaten Langkat. Penelitian ini merupakan penelitian deskriptif yang pengumpulan data secara retrospektif. Penelitian ini telah dilaksanakan dengan mengambil data resep dari Januari 2019 sampai Desember 2019. Populasi dalam penelitian ini adalah seluruh resep-resep yang ada di Puskesmas Tangkahan Durian Periode Bulan Januari sampai dengan Desember 2019 sebanyak 583. Pengambilan sampel menggunakan Total sampling sehingga besar sampel adalah sebanyak 583 orang. Hasil Penelitian didapat bahwa Obat antihipertensi yang tersedia di Puskesmas Tangkahan Durian adalah Amlodipine $10 \mathrm{mg}$, Captopril $25 \mathrm{mg}$ dan Nifedipine $10 \mathrm{mg}$, Presentase Penggunaan Obat Antihipertensi di Puskesmas Tangkahan Durian Periode Bulan Januari 2019 sampai dengan Bulan Desember 2019 yang paling sering diresepkan adalah Amlodipine 10 mg. Saran dalam penelitian ini diharapkan dengan adanya penelitian ini Puskesmas Tangkahan Durian terus berkontribusi memberikan pengobatan kepada masyarakat khususnya penyakit hipertensi untuk mencegah terjadinya komplikasi penyakit.
\end{abstract}

Kata kunci: Hipertensi, Peresepan, Obat Antihipertensi, Pasien Hipertensi

\begin{abstract}
Hypertension is a condition where there is an increase in blood pressure above the normal threshold. Hypertension needs to be treated, one of which is the effort to handle antihypertensives with pharmacological treatment of antihypertensives. This study aims to determine the quality of the generic drug product with the logo (OGB) of PT. Phapros Tbk Medan in the East Medan Region and to find out the Profile of Prescribing Antihypertensive Drugs for the Period of January 2019 to December 2019 at Tangkahan Durian Health Center, Berandan Barat District, Langkat Regency. This research is a descriptive study which collects data retrospectively. This research has been carried out by taking prescription data from January 2019 to December 2019. The population in this study is all the recipes in the Tangkahan Durian Community Health Center for
\end{abstract}


the period of January to December 2019 as many as 583. Sampling used total sampling so that the sample size was as much as 583 people. The results showed that the antihypertensive drugs available at Tangkahan Durian Health Center were Amlodipine $10 \mathrm{mg}$, Captopril $25 \mathrm{mg}$ and Nifedipine $10 \mathrm{mg}$, the percentage of use of antihypertensive drugs at Tangkahan Durian Public Health Center for the period from January 2019 to December 2019, the most frequently prescribed is Amlodipine $10 \mathrm{mg}$. Suggestions in this study are expected that with this research Tangkahan Durian Public Health Center will continue to contribute to providing treatment to the community, especially hypertension to prevent disease complications.

\section{Keywords: Hypertension, Prescribing, Antihypertensive Drugs, Hypertension Patients}

\section{Pendahuluan}

Hipertensi atau yang dikenal dengan nama penyakit darah tinggi masih menjadi masalah kesehatan di negara berkembang khususnya Indonesia. Hipertensi merupakan suatu keadaan dimana terjadi peningkatan tekanan darah di atas ambang batas normal yaitu 120/80 mmHg (Tarigan dkk, 2018). Hipertensi perlu mendapat perhatian khusus dari masyarakat mengingat dampak yang ditimbulkan baik dalam jangka pendek maupun jangka panjang, salah satunya adalah upaya penanganan antihipertensi dengan terapi pemberian farmakologis antihipertensi secara tepat sebagai suatu langkah yang strategis (Putri dkk, 2019).

Penggunaan obat dikatakan rasional bila pasien menerima obat sesuai kebutuhannya untuk periode waktu yang adekuat dan dengan harga yang paling murah.Faktor yang mempengaruhi kerasionalan penggunaan obat adalah pola peresepan, pelayanan yang diberikan bagi pasien, dan tersedianya obat untuk diberikan kepada pasien. Faktor peresepan berpengaruh langsung pada ketepatan pemberian obat yang akan dikonsumsi oleh pasien. Peresepan yang tepat akan berdampak pada keberhasilan terapi pada pasien. Peresepan yang ditulis harus sesuai dengan diagnosis serta tingkat keparahan penyakit yang diderita pasien tersebut. Pola peresepan penting dalam mencerminkan ketepatan terapi pada pasien hipertensi karena terapi yang tepat akan berdampak pada terkontrolnya tekanan darah pada pasien sehingga mencegah komplikasi penyakit hipertensi (Ambarwati, 2019). Berdasarkan data obat antihipertensi yang tersedia di Puskesmas Tangkahan Durian adalah amlodipine $10 \mathrm{mg}$, Captopril $25 \mathrm{mg}$ dan Nifedipine $10 \mathrm{mg}$. Obat antihipertensi yang paling sering diresepkan di Puskesmas Tangkahan Durian adalah Amlodipine $10 \mathrm{mg}$ dan Captopril $25 \mathrm{mg}$ (Profil Puskesmas Tangkahan Durian, 2019).

Berdasarkan wawancara kepada 10 orang pasien rawat jalan didapat bahwa 6 orang menyebutkan bahwa harga obat anti darah tinggi masih relatif tinggi dan masih adanya dokter yang menuliskan resep dengan nama dagang yang harus ditebus pasien, serta kurangnya pengetahuan masyarakat untuk mendapatkan obat hipertensi. Sedangkan 4 orang lagi tidak terbuka ketika ditanya. Berdasarkan permasalahan diatas peneliti tertarik ingin melakukan penelitian tentang "Profil Peresepan Obat Antihipertensi Periode Januari sampai dengan Desember 2019 di Puskesmas Tangkahan Durian Kecamatan Berandan Barat Kabupaten Langkat".

\section{Metode Penelitian}

Jenis penelitian ini merupakan penelitian deskriptif yang pengumpulan data secara retrospektif yaitu penelitian berdasarkan data peresepan obat Antihipertensi Periode 
Januari 2019 sampai dengan Desember 2019 di Apotik Puskesmas Tangkahan Durian Kecamatan Berandan Barat Kabupaten Langkat. Teknik pengambilan sampel menggunakan Total sampling. Penelitian ini telah dilaksanakan dengan mengambil data peresepan obat periode Januari 2019 sampai dengan Desember 2019. Populasi dalam penelitian ini adalah resep-resep dengan diagnosa hipertensi yang ada di Puskesmas Tangkahan Durian Periode Bulan Januari sampai dengan Desember 2019 sebanyak 583 resep. Data yang digunakan adalah data sekunder yaitu data yang diperoleh dari ruang apotik rawat jalan yang diberi informasi tentang jenis kelamin pasien, umur pasien, nama obat, golongan obat, dan dosis. Data yang diperoleh dianalisis secara deskriptif untuk mengetahui Profil Peresepan Obat Antihipertensi Periode Januari 2019 sampai dengan Desember 2019 pada pasien di Puskesmas Tangkahan Durian Kecamatan Berandan Barat Kabupaten Langkat yang meliputi golongan obat, dosis, dan kombinasi obat antihipertensi pada pasien hipertensi.

\section{Hasil dan Pembahasan}

Berdasarkan penelitian yang dilakukan maka diperoleh hasil sesuai dengan yang tertera pada tabel 1 di bawah ini.

Tabel 1. Profil Pasien berdasarkan Jenis Kelamin

\begin{tabular}{|c|c|c|c|c|c|c|c|}
\hline \multirow{3}{*}{ No } & \multirow{3}{*}{ Bulan } & \multicolumn{4}{|c|}{ Jenis Kelamin } & \multirow{2}{*}{\multicolumn{2}{|c|}{ Total }} \\
\hline & & \multicolumn{2}{|c|}{ Laki-Laki } & \multicolumn{2}{|c|}{ Perempuan } & & \\
\hline & & $\mathbf{F}$ & $\%$ & $\mathbf{F}$ & $\%$ & $\mathbf{F}$ & $\%$ \\
\hline 1 & Januari & 31 & 52,5 & 28 & 47,5 & 59 & 100 \\
\hline 2 & Februari & 15 & 34,8 & 28 & 65,2 & 43 & 100 \\
\hline 3 & Maret & 18 & 42,8 & 24 & 57,2 & 42 & 100 \\
\hline 4 & April & 25 & 43,9 & 32 & 56,1 & 57 & 100 \\
\hline 5 & Mei & 21 & 46,7 & 24 & 53,3 & 45 & 100 \\
\hline 6 & Juni & 28 & 52,8 & 25 & 47,2 & 53 & 100 \\
\hline 7 & Juli & 16 & 34,1 & 31 & 65,9 & 47 & 100 \\
\hline 8 & Agustus & 22 & 45,8 & 26 & 54,2 & 48 & 100 \\
\hline 9 & September & 30 & 56,6 & 23 & 43,4 & 53 & 100 \\
\hline 10 & Oktober & 21 & 50 & 21 & 50 & 42 & 100 \\
\hline 11 & Nopember & 22 & 44 & 28 & 56 & 50 & 100 \\
\hline 12 & Desember & 24 & 54,5 & 20 & 45,5 & 44 & 100 \\
\hline & Total & 273 & 46,8 & 310 & 53,2 & 583 & 100 \\
\hline
\end{tabular}

Berdasarkan tabel diatas mulai dari Bulan Januari 2019 sampai dengan Desember 2019 dapat dilihat bahwa sebagian besar jenis kelamin pasien yang berobat di Puskesmas Tangkahan Durian dengan masalah hipertensi adalah perempuan sebanyak 310 orang $(53,2 \%)$ dengan distribusi pada bulan Januari sebagian besar pasien adalah laki-laki sebanyak 31 orang $(52,5 \%)$, bulan Februari 2019 sebagian besar adalah perempuan sebanyak 28 orang $(65,2 \%)$, bulan Maret 2019 sebagian besar adalah perempuan sebanyak 24 orang $(57,2 \%)$, bulan April 2019 sebagian besar adalah perempuan sebanyak 32 orang $(56,1 \%)$, bulan Mei 2019 sebagian besar adalah perempuan sebanyak 24 orang $(53,3 \%)$, bulan Juni 2019 sebagian besar adalah laki-laki sebanyak 28 orang $(52,8 \%)$, bulan Juli 2019 sebangian besar adalah perempuan sebanyak 31 orang $(65,9 \%)$, bulan Agustus 2019 sebagian besar adalah perempuan sebanyak 26 orang (54,2\%), bulan September 2019 sebagian besar adalah laki-laki sebanyak 30 orang $(56,6 \%)$, bulan Oktober 2019 sama antara laki-laki dan perempuan dengan masing-masing sebanyak 21 orang (50\%), bulan Nopember 2019 sebagian besar adalah perempuan sebanyak 28 orang 
(56\%) dan bulan Desember 2019 sebagian besar adalah laki-laki sebanyak 24 orang $(54,5 \%)$.

Tabel 2. Profil Pasien berdasarkan Umur

\begin{tabular}{|c|c|c|c|c|c|c|c|c|c|c|c|c|c|}
\hline \multirow{3}{*}{ No } & \multirow{3}{*}{ Bulan } & \multicolumn{10}{|c|}{ Umur } & \multirow{2}{*}{\multicolumn{2}{|c|}{ Total }} \\
\hline & & \multicolumn{2}{|c|}{$\begin{array}{c}31-40 \\
\text { Tahun }\end{array}$} & \multicolumn{2}{|c|}{$\begin{array}{c}41-50 \\
\text { Tahun }\end{array}$} & \multicolumn{2}{|c|}{$\begin{array}{c}\text { 51-60 } \\
\text { Tahun }\end{array}$} & \multicolumn{2}{|c|}{$\begin{array}{c}61-70 \\
\text { Tahun }\end{array}$} & \multicolumn{2}{|c|}{$\begin{array}{c}71 \\
\text { Tahun }\end{array}$} & & \\
\hline & & $\mathbf{F}$ & $\%$ & $\mathbf{F}$ & $\%$ & $\mathbf{F}$ & $\%$ & $\mathbf{F}$ & $\%$ & $\mathbf{F}$ & $\%$ & $\mathbf{F}$ & $\%$ \\
\hline 1 & Januari & 0 & 0 & 6 & 10,2 & 7 & 11,9 & 29 & 49,1 & 17 & 28,8 & 59 & 100 \\
\hline 2 & Februari & 4 & 9,3 & 9 & 20,9 & 6 & 13,9 & 17 & 39,6 & 7 & 16,3 & 43 & 100 \\
\hline 3 & Maret & 3 & 7,2 & 2 & 4,7 & 8 & 19,1 & 17 & 40,5 & 12 & 28,5 & 42 & 100 \\
\hline 4 & April & 4 & 7,1 & 7 & 12,2 & 6 & 10,5 & 24 & 42,1 & 16 & 28,1 & 57 & 100 \\
\hline 5 & Mei & 2 & 4,5 & 4 & 8,9 & 10 & 22,2 & 14 & 31,1 & 15 & 33,3 & 45 & 100 \\
\hline 6 & Juni & 2 & 3,8 & 5 & 9,4 & 2 & 3,8 & 23 & 43,4 & 21 & 39,6 & 53 & 100 \\
\hline 7 & Juli & 4 & 8,5 & 10 & 21,3 & 9 & 19,1 & 18 & 38,3 & 6 & 12,8 & 47 & 100 \\
\hline 8 & Agustus & 3 & 6,3 & 9 & 18,7 & 4 & 8,3 & 20 & 41,7 & 12 & 25 & 48 & 100 \\
\hline 9 & September & 2 & 3,9 & 1 & 1,9 & 3 & 5,6 & 20 & 37,7 & 27 & 50,9 & 53 & 100 \\
\hline 10 & Oktober & 3 & 7,1 & 2 & 4,8 & 4 & 9,5 & 18 & 42,9 & 15 & 35,7 & 42 & 100 \\
\hline 11 & Nopember & 4 & 8 & 5 & 10 & 6 & 12 & 24 & 48 & 11 & 22 & 50 & 100 \\
\hline 12 & Desember & 3 & 6,8 & 6 & 13,6 & 2 & 4,5 & 17 & 38,7 & 16 & 36,4 & 44 & 100 \\
\hline & Total & 34 & 5,8 & 66 & 11,3 & 67 & 11,5 & 241 & 41,3 & 175 & 30,1 & 583 & 100 \\
\hline
\end{tabular}

Berdasarkan tabel diatas mulai dari Bulan Januari 2019 sampai dengan Desember 2019 dapat dilihat bahwa sebagian besar umur pasien yang berobat di Puskesmas Tangkahan Durian dengan masalah hipertensi adalah umur 61-70 Tahun sebanyak 241 orang $(41,3 \%)$ dengan distribusi pada bulan Januari 2019 sebanyak 29 orang (49,1\%), bulan Februari 2019 sebanyak 17 orang (39,6\%), bulan Maret 2019 sebanyak 17 orang (40,1\%), bulan April 2019 sebanyak 24 orang (42,1\%), bulan Mei 2019 sebanyak 14 orang $(31,1 \%)$, bulan Juni 2019 sebanyak 23 orang $(43,4 \%)$, bulan Juli 2019 sebanyak 18 orang (38,3\%), bulan Agustus 2019 sebanyak 20 orang (37,7\%), bulan September 2019 sebanyak 20 orang (37,7\%), bulan Oktober 2019 sebanyak 18 orang (42,9\%), bulan Nopember 2019 sebanyak 24 orang (48\%) dan bulan Desember 2019 sebanyak 17 orang $(38,7 \%)$.

Tabel 3. Obat Antihipertensi di Puskesmas Tangkahan Durian

\begin{tabular}{cc}
\hline No & Nama Obat \\
\hline 1 & Amlodipine $10 \mathrm{mg}$ \\
\hline 2 & Captopril $25 \mathrm{mg}$ \\
\cline { 2 - 2 } 3 & Nifedipine $10 \mathrm{mg}$ \\
\hline
\end{tabular}

Berdasarkan tabel di atas obat antihipertensi yang tersedia di Puskesmas Tangkahan Durian adalah Amlodipine 10 mg, Captopril 25 mg dan Nifedipine 10 mg. 
Tabel 4. Distribusi Frekuensi Presentase Penggunaan Obat Antihipertensi di Puskesmas Tangkahan Durian Periode Bulan Januari 2019 sampai dengan Bulan Desember 2019

\begin{tabular}{|c|c|c|c|c|c|c|c|c|c|}
\hline \multirow{3}{*}{ No } & \multirow{3}{*}{ Bulan } & \multicolumn{6}{|c|}{$\begin{array}{c}\text { Penggunaan Obat } \\
\end{array}$} & \multirow{2}{*}{\multicolumn{2}{|c|}{ Total }} \\
\hline & & \multicolumn{2}{|c|}{$\begin{array}{c}\text { Amlodipine } 10 \\
\text { mg }\end{array}$} & \multicolumn{2}{|c|}{$\begin{array}{c}\text { Captopril } 25 \\
\text { mg }\end{array}$} & \multicolumn{2}{|c|}{$\begin{array}{c}\text { Nifedipiner } 10 \\
\mathrm{mg}\end{array}$} & & \\
\hline & & $\mathbf{F}$ & $\%$ & $\mathbf{F}$ & $\%$ & $\mathbf{F}$ & $\%$ & $\mathbf{F}$ & $\%$ \\
\hline 1 & Januari & 28 & 47,5 & 17 & 28,8 & 14 & 23,7 & 59 & 100 \\
\hline 2 & Februari & 19 & 44,2 & 14 & 32,5 & 10 & 23,3 & 43 & 100 \\
\hline 3 & Maret & 18 & 42,8 & 15 & 35,7 & 9 & 21,5 & 42 & 100 \\
\hline 4 & April & 24 & 42,1 & 21 & 36,8 & 12 & 21,1 & 57 & 100 \\
\hline 5 & Mei & 18 & 40 & 15 & 33,3 & 12 & 26,7 & 45 & 100 \\
\hline 6 & Juni & 22 & 41,5 & 18 & 33,9 & 13 & 24,6 & 53 & 100 \\
\hline 7 & Juli & 18 & 38,3 & 15 & 31,9 & 14 & 29,8 & 47 & 100 \\
\hline 8 & Agustus & 18 & 37,5 & 17 & 35,4 & 13 & 27,1 & 48 & 100 \\
\hline 9 & September & 20 & 37,7 & 17 & 32,1 & 16 & 30,2 & 53 & 100 \\
\hline 10 & Oktober & 17 & 40,5 & 13 & 30,9 & 12 & 28,6 & 42 & 100 \\
\hline 11 & Nopember & 19 & 38 & 16 & 32 & 15 & 30 & 50 & 100 \\
\hline 12 & Desember & 17 & 38,6 & 15 & 34,1 & 12 & 27,3 & 44 & 100 \\
\hline & Total & 238 & 40,8 & 193 & 33,1 & 152 & 26,1 & 583 & 100 \\
\hline
\end{tabular}

Berdasarkan tabel diatas dapat dilihat bahwa Presentase Penggunaan Obat Antihipertensi di Puskesmas Tangkahan Durian Periode Bulan Januari 2019 sampai dengan Bulan Desember 2019 yang paling sering diresepkan adalah Amlodipine $10 \mathrm{mg}$ sebanyak 238 resep $(40,8 \%)$ dengan distribusi pada bulan Januari 2019 sebanyak 28resep (47,5\%), bulan Februari 2019 sebanyak 19 resep (44,2\%), bulan Maret 2019 sebanyak 18resep (42,8\%), bulan April 2019 sebanyak 24 resep (42,1\%), bulan Mei 2019 sebanyak 18resep (40\%), bulan Juni 2019 sebanyak 22resep (41,5\%), bulan Juli 2019 sebanyak 18 resep $(38,3 \%)$, bulan Agustus 2019 sebanyak 18resep (37,5\%), bulan September 2019 sebanyak 20 resep(37,7\%), bulan Oktober 2019 sebanyak 17resep (40,5\%), bulan Nopember 2019 sebanyak 19resep (38\%) dan bulan Desember 2019 sebanyak 17 resep(38,6\%).

\section{Kesimpulan}

Berdasarkan penelitian yang dilakukan di Puskesmas Tangkahan Durian dapat disimpulkan bahwa obat antihipertensi yang tersedia di Puskesmas Tangkahan Durian adalah Amlodipine $10 \mathrm{mg}$, Captopril $25 \mathrm{mg}$ dan Nifedipine $10 \mathrm{mg}$ dan presentase Penggunaan Obat Antihipertensi di Puskesmas Tangkahan Durian Periode Bulan Januari 2019 sampai dengan Bulan Desember 2019 yang paling sering diresepkan adalah Amlodipine $10 \mathrm{mg}$.

\section{Referensi}

Ambarwati. (2019). Pola Peresepan Obaat Antihipertensi pada Pasien Rawat Jalan di Poli Spesialis Penyakit Dalam RSUD Tidar Kota Magelang Periode MaretAgustus 2018. Skripsi Universitas Setia Budi. Surakarta :

Black, J dan Hawks, J. (2014). Keperawatan Medikal Bedah: Manajemen Klinis untuk Hasil yang Diharapkan. Dialihbahasakan oleh Nampira R. Jakarta: Salemba Emban Patria. 
Brunner \& Suddarth. (2014). Keperawatan Medikal Bedah.Edisi 8.Volume 2.Jakarta : EGC

Irianto Koes. (2014). Ilmu Kesehatan Masyarakat. Bandung: Alfabet.

Kementerian Kesehatan Republik Indonesia. (2018). Pusat Data dan Informasi tahun 2018. Jakarta.

Masriadi. (2016). Epidemiologi Penyakit Tidak Menular. Jakarta : TIM Syahrini, Erylna Nur., Susanto, Henry Setyawan., Udiyono, Ari. 2012 Faktor-Faktor Risiko Hipertensi Primer di Puskesmas Tlogosari Kulon Kota Semarang.Jurnal Kesehatan Masyarakat. Vol 1, 2012: pp. 315 - 325.

Oktaviani, O. (2016). Metode Time Management terhadap Waktu Tunggu Pasien di Bagian Loket Pendaftaran di Puskesmas Bandarharjo Semarang Tahun 2016.Universitas Dian Nuswantoro.

Profil Dinas Kesehatan Sumatera Utara. (2016). Medan.

Profil Puskesmas Tangkahan Durian. (2019). Langkat.

Putri, L. S. A, Satriyana, B. K dan Jawi, I, M. (2019). Gambaran Pola Penggunaan Obat Antihipertensi pada Pasien Hipertensi di Instalasi Rawat Inap RSUP Sanglah Denpasar Tahun 2016.Jurnal Medika Udayana, Volume 8 Nomor 6. ISSN : 2597-8012.

Saferi W, Andra., Mariza P, Yessie. (2013). KMB 2 :Keperawatan Medikal Bedah (Keperawatan Dewasa Teori dan Contoh Askep). Yogyakarta : Nuha Medika.

Sari, R. D. (2009). Evaluasi Peresepan Obat Antihipertensi Antara Pasien Umum dan Pasien Peserta Askes di Instalasi Rawat Jalan RSUP Dr. Sardjito Yogyakarta Bulan Januari - Juni 2008. Skripsi.Universitas Sanata Dharma.Yogyakarta :

Smeltzer \& Bare. (2012). Buku Ajar Keperawatan Medikal Bedah Brunner dan Suddarth (Ed.8, Vol. 1,2). Jakarta : EGC.

Tarigan, A.R dkk. (2018). Pengaruh Pengetahuan, Sikap dan Dukungan Keluarga Terhadap Diet Hipertensi di Desa Hulu Kecamatan Pancur Batu Tahun 2016. Jurnal Kesehatan. Vol.11 No.1 P-ISSN :2086-2555; E-ISSN: 26227363.

Wijaya, A.S dan Putri, Y.M. (2013). Keperawatan Medikal Bedah 2, Keperawatan Dewasa Teori dan Contoh Askep. Yogyakarta : Nuha Medika 